\title{
Product Innovation Design Method Based on Case Reasoning
}

\author{
Chen Wei ${ }^{1,2}$ \\ ${ }^{1}$ Art institute of building environment \\ Sichuan vocational college of science and technology \\ ${ }^{2}$ Department of environment engineering \\ Southwest Jiaotong University Chengdu 610031, China \\ 271768825@qq.com
}

\author{
Fan Juan \\ Art institute of building environment \\ Sichuan vocational college of science and technology \\ Chengdu 610031
}

\begin{abstract}
In order to coordinate the product innovation design method and the market economy benefit, it is necessary fully inherited the advantages of similar products. According to the product innovation design theory of evolution, and the thought of case-based reasoning and cognitive psychology, it is analyzed product case information based on the theory of CBR; it is summed up the model of mechanical and electronic products innovation design method synthetically. It is presented the practical method of modeling innovative design of mechanical and electronic products and computer aided technology. It contains the innovation questions, the solving process of industrial design framework and context reasoning model. Taking the CNC machine tool as the object, the model from the situation and three aspects of knowledge expression, is build a preliminary case based on computer aided industrial design system, and it is applied to the design practice. The actual show that the method is in conformity with the world's innovation trend.
\end{abstract}

Keywords-industrial design; case reasoning design; situation cognitive; knowledge of CNC machine tools

\section{INTRODUCTION}

Product innovation design problems have many specific conditions limit, the contradiction between inheritance and then create problems, it is difficult to quickly and accurately choose among design concepts and suitable for the market to carry on the redesign. Research innovation design method based on case-based reasoning, through many cases to find out the advantages and disadvantages of existing products, design and innovation, improve the efficiency of design, it is necessary to improve product design.

Case-based reasoning theory of CBR, is a method of design of artificial intelligence [1], according to the case or practical experience of the past, reasoning, get the current case solution. Based on the experience of similar products, is a good way to improve innovative design. Agngino[2] is proposed to design example through the media technology interface for users browse, research or confirmation of information, standard of using the Internet and a robust structured query language (SQL) database with the CAD component to create a conceptual design information server [3-4] of Nanjing university of aeronautics and astronautics xu according to the characteristics of the engineering machinery products, the process design of CBR, representation, retrieval,

Sponsor: The natural science foundation of Science and Technology Agency of Sichuan province, (2014FZ0112). modification, case learning and maintenance, and through the establishment of the extended object model, presentation and storage engineering machinery product design case of complete information, build and implement the combination based on assembly decomposition hierarchy tree index of engineering machinery products are putted forward. [5] Although the domestic research on CBR has made great progress, but in terms of CBR combined with innovation theory, still no progress.

Based on the idea of case-based reasoning in order to improve the innovation theory as the foundation, proposed the concept of "design innovation based on the case", built a computer aided industrial design system based on the case, and concrete is studied by using this system, the design practice, the model is verified with the system.

\section{THE CASE OF PRODUCT INNOVAtion DESIGN THEORY}

\section{A. Product innovation design theory}

There are dozens of the definition of innovation, choose one of the simplest definitions: innovation is a kind of better ways of doing things, a way to improve and evolve. Product innovation need to content and form, namely the transformation has some product shape or functions, transforming idea, culture idea of the product and market continuously satisfy the spiritual needs and material needs of consumers. Being improved, evolution, much easier than creating theory, create products, also easy to implement into practice, innovation becomes a theory of no burden of actual behavior.

Whatever the innovation, the ultimate goal is to the embodiment of the product value, drive the enterprise economic growth. The traditional industrial design is to consider the use of the people, aesthetic, emotional design and innovation of the era of industrial design should contain appearance, and the purpose of the product information, culture, market and other systematic design. Excellent industrial design includes the entire contents of the actual product, significant, is of the important factors of the success of the enterprise in the competition. As the market's emphasis on industrial design, product innovation design becomes an important part of the enterprise development strategy. Product innovation design to improve the competition advantage, and promote industrial development and social progress, improve 
economic efficiency, leads the spirit of enterprise logo, etc., is of great significance.

\section{B. Based on case-based reasoning}

Based on Case Reasoning (Case -based Reasoning, CBR) theory originated in the $1970 \mathrm{~s}$, is the development of artificial intelligence have sprung up in the process of a kind of method, is a kind of practical experience from the past experience or Reasoning. Through the former because of its chain structure, such as the chain rule, derived the conclusion of a process, understanding of the reasoning of reasoning is the traditional views, this chain of reasoning rules method was used by many expert system. Case-based reasoning is a method of completely different, it is mainly used the information rather than rules. Case the word exists in the different translation of words in Chinese literature, such as source example, example, instance, examples, Case, etc., the article unified referred to as a Case. Generally, a problem with a case study in CBR said state description and solution strategy. Case in the case according to certain mode to organize and store, when new problems, system according to the similarity measure and matching strategy and index strategy, in the case retrieval with the current problems with the most similar case sets, and according to the direction of innovation, change its solution strategy, make its solving best fit the requirements of the current problems, the final solution strategy and new problems as a new case in the case, for future needs.

From the perspective of cognitive science to explore human reasoning and learning mechanism is based on the research on the origins of the case based reasoning, from the child's simple thinking to experts careful decisions, make all kinds of affairs through human unconscious or conscious memory, in fact people often and are good at using case-based reasoning. CBR is applied in the research and application of artificial intelligence such reasoning method based on experience. An important technology in the field of industrial design and problem solving method is the CBR. Have a very tempting prospects, will be the basic ways of knowledge system in the 21 st century.

\section{THE CASE STUDY OF INDUSTRIAL DESIGN SITUATION}

\section{A. Industrial design framework}

Design is a problem solving process from requirements to target. For design knowledge, can be viewed as a behavior domain, functional domain and physical domain design framework and process areas. Focus on industrial design, appearance and communication of information, the purpose of the product is in the field of design in order to consider the use of the people, aesthetic, emotional design. Industrial design focuses on users field are mainly concentrated in aesthetic aspect of product demand, its functional domains embodies on the aesthetic function and shape constraints. Aesthetic products including meet the needs of the physical functions and meet the needs of people's emotional level, the former performance for use and easy to use, to use, and other products of material function, which show the style characteristics, product category and brand image and other emotional function.
Industrial design framework is behavior domain, functional domain and physical domain and process areas of mutual mapping framework. Due to industrial design involves a large number of image thinking and people's aesthetic and emotional problems demand and hard to quantify, the design result is closely related with morphology, model, at the same time, its demand and function domains descriptions, and the mapping relationship to physical domain relative to the fuzzy and complicated, USES the existing functional domain and physical domain to build the relationship between design model and knowledge expression has the certain difficulty. Therefore, on the basis of the process area in front of the building design case to express three domains reflect design knowledge, and then construct the industrial design to design the knowledge model.

\section{B. Design situation}

Design situation from the concept of "situated cognition" research in cognitive psychology, the study found people's cognition is associated with the personal experience of a particular time and place, to a certain situation cognitive ever experience. Situation from the point of view, based on the case design is a carrier of knowledge, not only contains is directly related to design knowledge, and to some of the most difficult to express directly to express knowledge through case situation, characterized by a "process areas" or the operational layer on the surface of the knowledge. Design situation better solve the problem of industrial design domain and their mapping relation expression, which has more knowledge capacity.

According to the design process of problem solving, a complete design context contains three child situations: problem situation, to solve the situation and situation. Three child situations respectively represent the three main stages in the process of design problem solving, contains the designers in the design process to the design of the relationship between different objects (products).

(1) the description of the problem situation is the initial state to the design problem, the design is the designer of the information access and the collection and analysis of the design problem and explore. In the problem situation, design issues, design conditions, and other limiting factors is the key of the situation to express.

(2) to solve the situation is the designer according to the design information and design problems, combined with its design experience, the design problem is converted into the process of design solutions. To solve the situation is a description of the design process, is a design process of external knowledge into the product. In solving the situation, the designer's solution strategy, method and solving steps is one of the most important aspects of the situation to express.

(3) the solution situation is a problem for the description of the target state, is the result of design knowledge externalization. In circumstances of solution, the focus of the design result is situation expression, industrial design, in particular, because the solution contained in the emotion and image thinking problem, it is one of the difficult points of expression. 


\section{INDUSTRIAL DESIGN SCENARIO MODEL BASED ON THE CASE}

\section{A. Industrial design framework}

Industrial design based on case situation model is according to the characteristics of the industrial design field design situation structure and reasoning, including two aspects of situational organizational framework and context reasoning model. Industrial design scenario organization includes knowledge acquisition and knowledge using two levels.

In the aspect of knowledge acquisition, as a result of designer needs through a retrieval way for final design case, so directly on the design situation of three child situation, namely the problem situation, to solve the situation settlement situation respectively. Each design scenario is a situational attributes and their descriptions (value) of a hierarchical network. Situational characteristics and describe the relationship between value is not a couple relationship, due to but is organized according to certain rules. For example, for the problem situation is through the "problem character set" and "problem description" to express the membership degree of relationship between.

Designers at the knowledge level, mainly through using the method of design case, tool case even the result of the design to complete the design task, organizations should therefore situation with one or several specific complete problem solving process - the organization design case. A design case contains three children in a situation in which each situation in the level of a situation description, combined with the process parameters, to form a complete "' problem solving, solution design problem solving process, show that industrial design process of a product.

Because of the industrial design is a kind of typical multiple solution problem solving process, from the whole product development process, the same rounds problem situation is the same or similar. So the same rounds problem situation of several design cases, forming a "problem solving" case. Rounds of design situation can be expressed as the wheel I design problem situation, the wheel I no $\mathrm{k}$ scheme to solve the situation, the first round of the first number $k$ plan situation. From the whole product development process, the case can be expressed as each round design problems, to solve the situation and situation of the circulation.

\section{B. The industrial design context reasoning model}

Industrial design process is based on the situation of the similarity comparison, access to the most similar design case, in the case involving the conversion between design situation, namely case internal transformation; Design situations, and through the transformation from a case to another case, namely the transformation between case, loop iteration, the generation process of a new case. Inference model of a typical industrial design situation, including industrial design context reasoning of the four main stages: transformation, case retrieval, case in situation between conversion (new case generated) and case application.

(1) Retrieval. Retrieval is the starting point of case-based reasoning, the situations of industrial design, mainly includes two kinds of concept retrieval and data driven retrieval. Concept driven retrieval for design solved step by step, the fuzzy problem of motivation and systematization. Concept driven retrieval for design solved step by step, the fuzzy problem of motivation and systematization. Data driven retrieval directly search the design results, product modeling, including mainly the retrieval function domain and the physical domain search.

(2) In case situation. When designers retrieved after a case, the case can be involved in the problem, solving the settlement three child situations to carry on the knowledge acquisition; this requires the designer in the case of these three situations, to gain knowledge of the situation.

(3) The situation transformation between the cases. Because the designers at design time may need to learn from the advantages of several design cases, such as the modelling of reference solution 1 color scheme 2 , so need to change to another case, in some cases for other case situation and knowledge.

\section{INDUSTRIAL DESIGN SitUATION Model INSTANCE}

\section{A. The problem situation}

Industrial design situation model expression is mainly to the design of the three child situation. In NC machine tool as an example, discusses the situation of industrial design expression. Industrial design problem description is very fuzzy and uncertainty, the more performance for a language to describe design constraints and design Suggestions, such as the design style is consistent, "parts design considerations and the overall relationship coordination, etc. Based on fuzzy semantic description "problem character" building situation, which is set to "the problem characteristics" and the "problem description" between the membership degree, and express the problem situation.

TABLE I. A CNC MACHINE TOOL DESIGN AND ITS CHARACTERISTICS FOR MEMBERSHIP GRADE

\begin{tabular}{|c|c|c|c|c|c|c|}
\hline $\begin{array}{c}\text { Question } \\
\text { number }\end{array}$ & Process & $\begin{array}{c}\text { Parts overall } \\
\text { relationship }\end{array}$ & Material & $\begin{array}{c}\text { Man-machine } \\
\text { engineering }\end{array}$ & Function & Structure \\
\hline CP1260-1 & 0.42 & 0.32 & 0.10 & 0.16 & 0.22 & 0.50 \\
\hline C P1260-2 & 0.00 & 0.04 & 0.21 & 0.00 & 0.00 & 0.78 \\
\hline C P1260-3 & 0.00 & 0.00 & 0.05 & 0.12 & 0.00 & 0.00 \\
\hline
\end{tabular}

Combined with NC machine industrial design issues and requirements, set to industrial design characteristics, can be determined based on semantic similarity, using the methods of expert evaluation, the characteristics of relevant design problems and similarity evaluation factor set, set to get design language description and characteristics between the membership degree, as shown in table 1. 
CNC machine tool design characteristic factors according to the characteristics of NC machine industrial design, with a total of 15 , membership degree score $0-1$ points, 0 said membership degree 0.1 minute said directly subordinate relations.

With a concept driven retrieval, designers can search directly to the design problem of characteristics, in turn, get with the most similar design case to solve the current problems, implementation of the current problem solving process step by step.

\section{B. to solve the situation of the expression}

To solve the situation shows that a state change process is an object of action, and action. To solve the situation can be expressed as a way of solving (verb) and solve the matching matrix is constructed object (a noun).

NC machine industrial design problem solving process, there are two basic level strategy level and the object manipulation. The former is a term used to describe a macro means to solve the problem, the latter for industrial design elements, including whole and parts, dealing with the micro level. In general, industrial design strategy can be divided into three types:

(1) to deal with the original ones and the current design product relations strategy.(2) deal with the current design of the product strategy of the internal relations.(3) handle other factors in the field of the relationship between strategy. Table 2 sample for NC machine tools class strategy classification.

TABLE II. CNC MACHINE (1) CLASS STRATEGY CLASSIFICATION OF WORDS

\begin{tabular}{|c|c|c|c|}
\hline Behavior & Degree of innovation & Explain & Commonly used expression \\
\hline keep & inheritance & The same & Maintain, still use, Continue, lineage \\
\hline Adjust & To improve & Part of the improved & Add, change \\
\hline create & innovation & Completely change or Create new solution & The pursuit of, reflect, to seek, to form \\
\hline
\end{tabular}

Modelling element processing can be classified according to the model element processing results. In terms of overall modelling strategy, because of the characteristic of the industrial design problem solving thinking in images, the modelling approach commonly used graphics situation in the form of expression. As for NC machine tools, its modelling element processing overall effect can have two types of "light" and "stable", its processing characteristics of knowledge expression and their descriptions are as follows: "light", closed bottom (small) under the big, waist, and reduce the bearing surface, increase vertical segmentation; "Stable", the top (small) on the next big, increase the waist line, increase the bearing surface, increase the horizontal split.

For NC machine tool parts appearance modelling, parts of the processing according to the parts of the expression, and the overall treatment method for its characteristic factor can be expressed as "membership", "restricted", and "impact" and so on. In terms of "membership", for example, window belonging to the door, the door belongs to cover. Subordinate relations in fact are the strategy of solving the parts design.

\section{Concept expression}

Concept expression is an important part of the industrial design knowledge representation, involving several problems related to image thinking, characterized by the aesthetic function of the industrial design domain, domain, mainly including style attributes, brand attributes and structure properties.

Style attributes by the design of the solution in the style of "matrix" is described, and the coordinates of the point of matrix, the style expressed in this space point position a product modelling style, point coordinate values reflect the index of product style, is a perceptual image quantitative way, "solve $\mathrm{K}$ style coordinates" is a description of the corresponding NC machine tools of this style.
Brand attributes by some individual products with the same brand in the style of the matrix clustering points, including the product's brand style, the style of the product B $\mathrm{K}$. Brand attribute matrix by brand style area and to express the relationship between the product $\mathrm{x}$ brand position: the coordinates of the products in the style of matrix, the style of the brand matrix regional center coordinates, the style of the brand matrix area radius of center distance matrix $\mathrm{K}$ and the brand style.

Structural properties are the important factors influencing the NC machine tool modelling. Product modeling must reflect the structure and function of the product. For NC machine tools shape the structure of the biggest influence factors including the size of the machine type, the spindle and table and stroke, knife library, numerical control system configuration, etc.

For industrial design, the structural properties of expression is not only the expression of the structure itself, more important is how to structure and limit the expression of the knowledge of the product modeling, which expresses the structure parameters, model and mapping parameters.

Products generally includes the characteristics of external and internal, external characteristics including subjective modelling, the material, structure, technology and function, also is the so-called "form"; And many inherent features, this paper extracted the interactivity, love, sex, security, portability, ease of use, green sex and interesting seven characteristics, known as "god", establishing evaluation factor set according to these two characteristics: comprehensive functions, and new technology, new material, beautiful appearance. Therefore, the most important needs of conceptual design is the concept and the product structure ingenious combination.

For seven characteristics of "god", the final score disparity between the elements. For seven characteristics of "god", the final score between its elements among them is a smaller gap, the higher percentage of green and interest, followed by 
interactivity and ease of use, the lowest for security. Therefore, from the characteristics of the "god" products into consideration, during the design process should pay attention to environmental protection and saving material, make the product more interesting at the same time, give people a friendly feeling. At the same time, in the process of conceptual design, should consider many aspects increase the characteristics of "god". On this basis, the designer can also to evaluate several solutions, choose the most suitable scheme for further adjustment and design.

\section{APPLICATIONS}

\section{A. The problem situation}

Industrial design based on the case, on the basis of situation model and its expression in NC machine tools, set up a computer aided industrial design system based on case CNC machine CBID system (hereinafter referred to as the CBID system).The system includes four basic modules: search module, situation module, assessment module, modify, and storage module.

Retrieval module mainly is used to retrieve the corresponding case for designers. Each may be by some method to retrieve the situation. According to experimental research, found that when the designers in the face of a design problem is almost not retrieve some strategy to solve the problem of the directly, so the design retrieval entrance retrieval and retrieval of two parts including problem, corresponding concept drive and data driven two types of problem solving. For solution to retrieve, for example, the designer through input solution situational factors, such as silhouette, style and structure parameters, etc., can be retrieved situation has the largest similarity solution. When retrieving after entering a situation, when to convert the case situation, in addition to retrieval reconciliation retrieval increased strategy retrieval problem. Express child module is the main way that designers knowledge acquisition and application. Designers can is a development process in a solution or the context switching and jump, and can according to need to adjust the parameters to get a new design scheme. For example, in accordance with the key components of the retrieved interchangeable nc machine parts.

Situation in the module set up a problem situation, to solve the situation settlement situation three cases situation module. Such as the style of a CNC lathe properties can be expressed by coordinates and numerical. Case module structure of virtual $3 \mathrm{~d}$ demo page, designers can refer to the Solidworks model from a different Angle, obtain design knowledge.

Evaluation module can be right to have the case and the designers' design scheme for evaluation. CBID man-machine engineering evaluation module can design to machine tool components such as handles, window layout design for evaluation. The user can also enter the modify module case modify or create new case, for meet the demand of solution, and by storing module will plan after processing, storage in putted forward to form a new case and design situation. Use of this system has been for 10 domestic machine tool makers for NC machine tools shape design, some of these products has been put into production. Using the CBID system, it is completed to design the shape of covering parts outside of NC machine tools. it gets the consistent high praise at the Beijing international machine tool exhibition on display. Industrial design based on case situation model is verified and the feasibility of application of CBID system.

\section{CONCLUSION}

A complete CBR system is a huge system, especially some advanced algorithms, the new media technology used in combination with CBR. Due to the author the theoretical level, development experience and the development time is very limited, although the theory of CBR were studied, and the model has been applied in product modeling design, but the work is still in the primary stage of the article, still need further discussion and the research content. For industrial design research involves the problem of image thinking, has been the difficulties of design research. Used in the field of cognitive psychology and case-based reasoning are two research foundation, combined with the related experimental research, industrial design based on case situation model is put forward, and the design process and design pattern has carried on the rational modeling knowledge, and apply to the actual design activities, has obtained the good effect.

Because of the complexity of the industrial design problem and design process, particularly those involving part of image thinking there are still many problems remain to be research, such as analogy to the specific mechanism of the concrete form of the situational model transformation, industrial design requirements modeling, generation mechanism of the new situation, further research is in progress at present.

\section{REFERENCES}

[1] Pahl G, Beitz W, Schulz H et al. Engineering design: a systematic approach. Springer, 2007.

[2] Wallace $\mathrm{K} \mathrm{M}$, Blessing L T. Observations on some German contributions to engineering design in memory of Professor Wolfgang Beitz. Research in Engineering Design. 2000, 12(1): 2-7.

[3] Tsai S, Childs P R. TRIZ: Incorporating the Bright Process in Design. in: TRIZ-Future Conference. 2008. 243-250.

[4] Shiau J, Li X. A closed-loop design change control workflow in product data management for conceptual design phase. International Journal of Intelligent Control and Systems. 2007, 12(1): 24-36.

[5] Ian Watson. CBR is a Methodology not a Technology Research \& Development in Expert Systems[J]London Springer Publishing House, 1998: 213-223

[6] Y.Altintas,K. Eykorkmaz. Feedrate Optimization for Spline Interpolation in High Speed Machine Tools[J]. CIRP. 2003,52(1):288305. Zhang bin. Psychological contract theory and the knowledgestaff management [J].Shandong Social Science,2006(11):145-146.

Author introduction: Chen wei, male, born in September 1983, graduate student, lecturer, main research direction for product design theory research, He is in charge of one provincial scientific research project 